\title{
Evaluation of using membrane bioreactor for treating municipal wastewater at different operating conditions
}

\begin{abstract}
Membrane bioreactors (MBRs) can replace the activated sludge process and the final clarification step in municipal wastewater treatment. The combination of biological degradation with membrane filtration allows for high reduction of chemical oxygen demand (COD), biochemical oxygen demand (BOD), and ammonia nitrogen (NH3-N). In this paper, a laboratory-scale membrane bioreactor was fed with synthetic wastewater to investigate the possibility of simultaneous removal of organics and nitrogen. The degradation of synthetic wastewater at a hydraulic retention (HRT) time of $8 \mathrm{~h}$ has been studied. Three different concentrations of COD of the influent were investigated and the averages of these concentrations are 606, 1440 and $2500 \mathrm{mg} / \mathrm{L}$. The initial range of BOD and NH3-N were, 471.6 to $1888.6 \mathrm{mg} / \mathrm{L}$ and 19.455 to $53.609 \mathrm{mg} / \mathrm{L}$ respectively. Sludge retention time (SRT) was varied between 30 and 35 days. Mixed liquor suspended solids (MLSS) was ranged between 9980 and $26,720 \mathrm{mg} / \mathrm{L}$. Results showed that removal efficiencies for the MBR varied from 97.8 to $99.9 \%$ for COD, 98.9 to $99.9 \%$ for BOD and 91.0 to $99.9 \%$ for NH3-N. $\mathrm{pH}$ of the effluent was increased compared with $\mathrm{pH}$ of the influent but it was not exceeded the effluent discharge standards to Malaysian inland waters ( $\mathrm{pH}$ range from 6.0 to 9.0).
\end{abstract}

Keyword: Membrane bioreactor (MBR), Synthetic wastewater, COD removal, BOD removal, NH3-N removal 